\title{
Evaluation of the Accuracy of Conventional and Digital Methods of Obtaining Dental Impressions
}

\author{
Evaluación de la Exactitud de los Métodos Convencionales \\ y Digitales de la Obtención de Impresiones Dentales
}

\begin{abstract}
Thaise Ferreira Carvalho'; Jozely Francisca Mello Lima²; Jefferson David Melo de Matos ${ }^{3}$; Guilherme da Rocha Scalzer Lopes $^{4}$; John Eversong Lucena de Vasconcelos ${ }^{5}$; Lucas Villaça Zogheib ${ }^{6}$ \& Daniel Sartorelli Marques de Castro ${ }^{7}$
\end{abstract}

CARVALHO, T. F.; LIMA, J. F. M.; DE MATOS, J. D. M.; LOPES, G. R. S.; DE VASCONCELOS, J. E. L.; ZOGHEIB, L. V. \& DE CASTRO, D. S. M. Evaluation of the accuracy of conventional and digital methods of obtaining dental Impressions. Int. J. Odontostomat., 12(4):368-375, 2018.

ABSTRACT: The aim of this study was to carry out a literature review on the accuracy of conventional and digital dental impression methods, as well as present the various three-dimensional intraoral scanning systems. A bibliographic search was carried out in PUBMED's main health database, in which works published between 2008 and 2018 were collected. Laboratory studies, case reports and systematic reviews were included, addressing topics that deal with conventional digital materials, impression and precision. Articles that did not evaluate impression materials, their behavior and techniques to obtain a good impression of oral structures were excluded. Through a review in the literature, obtained the following findings: the most critical stage in macking a dental prothesis is to take the dental impression. The conventional technique of impression consists of obtaining a negative copy of the intra-oral situation that will be poured into gypsum, obtaining a positive copy, on which the work will be carried out. Digital scanning systems were not superior to conventional moldings when comparing fidelity, accuracy and detail reproduction; in contrast, they were superior to conventional impression when considering clinical chair time, patient and operator preference, and patient comfort.

KEY WORDS: dental impression technique, technology, dental, printing, three-dimensional.

\section{INTRODUCTION}

The purpose of dental impression is to copy the patient's intraoral situation, transforming it in a model. Obtaining a model of good quality and true to the original are extremely important for the success of the treatment; different types of materials and impression techniques have been used over the years to achieve this desired accuracy. The quality of a dental impression is determined by two factors: fidelity and precision (Aragón et al., 2016).
The first impression material was developed in 1937 denominated Agar, which is a reversible hydrocolloid with low precision and very complex handling technique. After that, alginate was created, which is an irreversible hydrocolloid, which had a disadvantage as a low dimensional stability. In 1950, the polysulfides or mercaptans were developed to solve some hydrocolloid problems. However, these substances had an unpleasant taste and odor that were not well accepted by patients (Baba et al., 2014).

\footnotetext{
${ }^{1}$ Post Graduate Student, Bauru Dental School, University of São Paulo, FOB/USP, Bauru - SP, Brazil.

2 Professor of Prosthodontics, Department of Dentistry, Universidade Federal do Ceará UFC, Sobral - CE, Brazil.

${ }^{3}$ Post Graduate Student, Masters Degree Program, Department of Prosthodontics, Universidade Estadual Paulista Júlio de Mesquita Filho UNESP, São José dos Campos - SP, Brazil.

${ }^{4}$ Post Graduate Student - PhD Program, Department of Prosthodontics, Universidade Estadual Paulista Júlio de Mesquita Filho UNESP, São José dos Campos - SP, Brazil.

${ }^{5}$ Professor of Oral Implantology, Department of Dentistry, Centro Caririense de Pós-Graduação CECAP, Juazeiro do Norte CE, Brazil.

${ }^{6}$ Professor of Prosthodontics, Department of Dentistry, Universidade de Fortaleza UNIFOR, Fortaleza - CE, Brazil.

${ }^{7}$ Professor of Prosthodontics, Department of Dentistry, Centro Universitário Cristus UNICHRISTUS, Fortaleza - CE, Brazil.
} 
In 1965, the polyether was developed, being the first elastomeric material developed specifically for dentistry. This material presented excellent characteristics such as: relatively fast chair time, excellent fluidity and detail reproduction, hydrophilic and high modulus of elasticity (Bauman et al., 2011). Then, the silicones were created by addition and condensation, the addition silicones exhibit a high modulus of elasticity, excellent tear strength, high stability, allowing the mold not to be melted. Regardless of the accuracy of impression materials, other factors can cause distortions in the models, such as: the impression technique, temperature variations that the molds undergo during transfer from the dental office to the laboratory (Birnbaum \& Aaronson, 2008).

Finally, in response to this quest for maximum accuracy and fidelity, and attempting to solve all problems showed in impression materials of the last decades, the intraoral digital scanning system was developed; according to this system, the intraoral situation is analyzed by means of a three-dimensional system, which creates a virtual model, where the prostheses will be made. The advantages of the intra-oral scanning technique are: better patient acceptance, reduction of distortion in impression materials, visualization of threedimensional preparation, reduction of clinical time (Christensen, 2009).

Digital scanning proposes to overcome some errors associated with conventional dental impression taking such as: inadequate pressure during molding, patient movement during molding, and operator ability. In addition they are more comfortable to the patient and reduce the need to redo a dental impression more than once (Christensen, 2008).

This study aimed to review the literature on the accuracy of conventional and digital methods of dental impression, as well as present the various three dimensional digital impression systems.

\section{MATERIAL AND METHOD}

A bibliographic search was conducted in the main PUBMED database (www.pubmed.gov), which collected studies published from 2008 to 2018. Laboratory studies, case reports and systematic reviews were included and, therefore, excluded articles that did not deal with the impression materials and how they did not behave, even the evolution and the ways of how to get an impression of the mouth structures.

We selected 45 articles (Figs. 1 and 2). The following titles of specific medical subjects and keywords were used: Dental Impression Technique ([MeSH Terms]); Technology, Dental ([MeSH Terms]); Impression, Three-Dimensional ([MeSH Terms]).

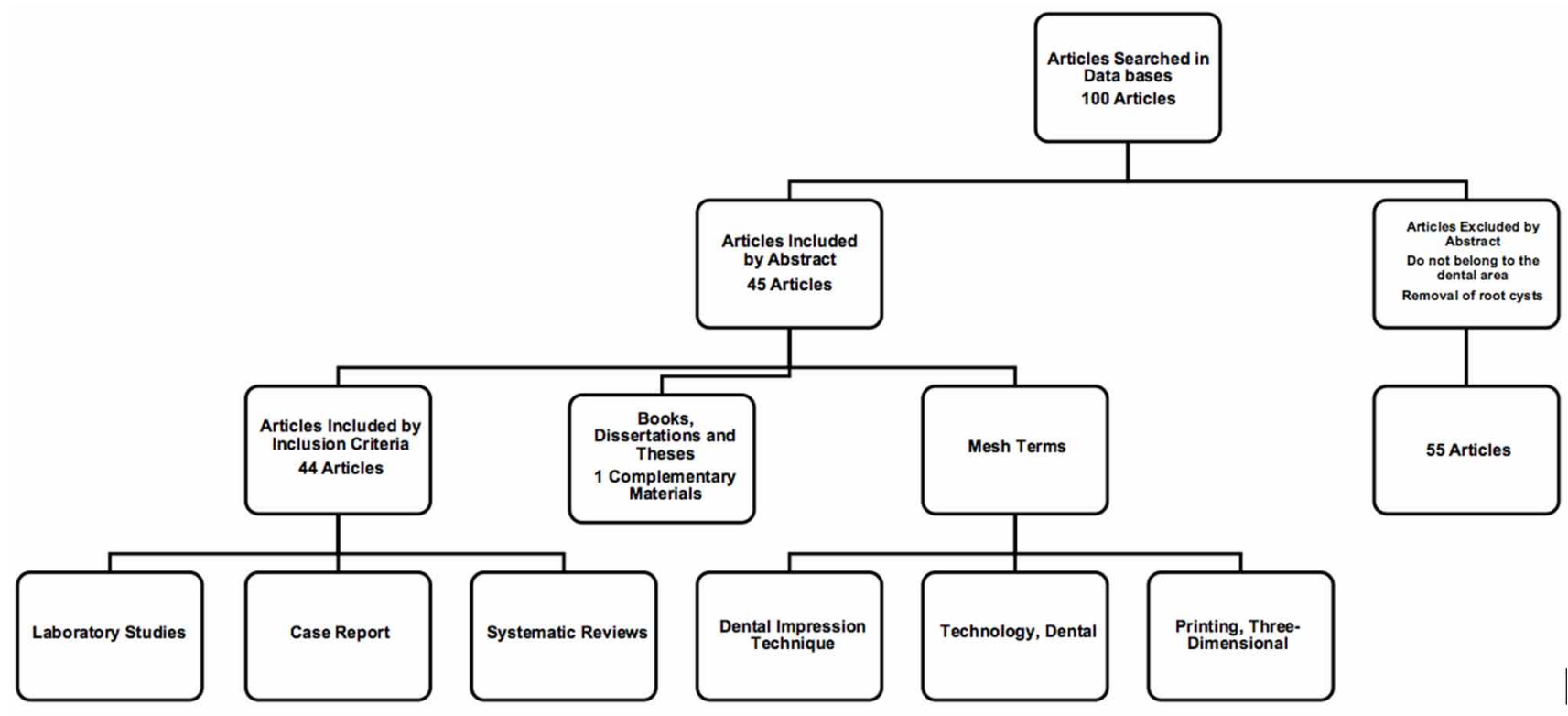

Fig. 1. Flowchart of the criterion of inclusion of articles. 


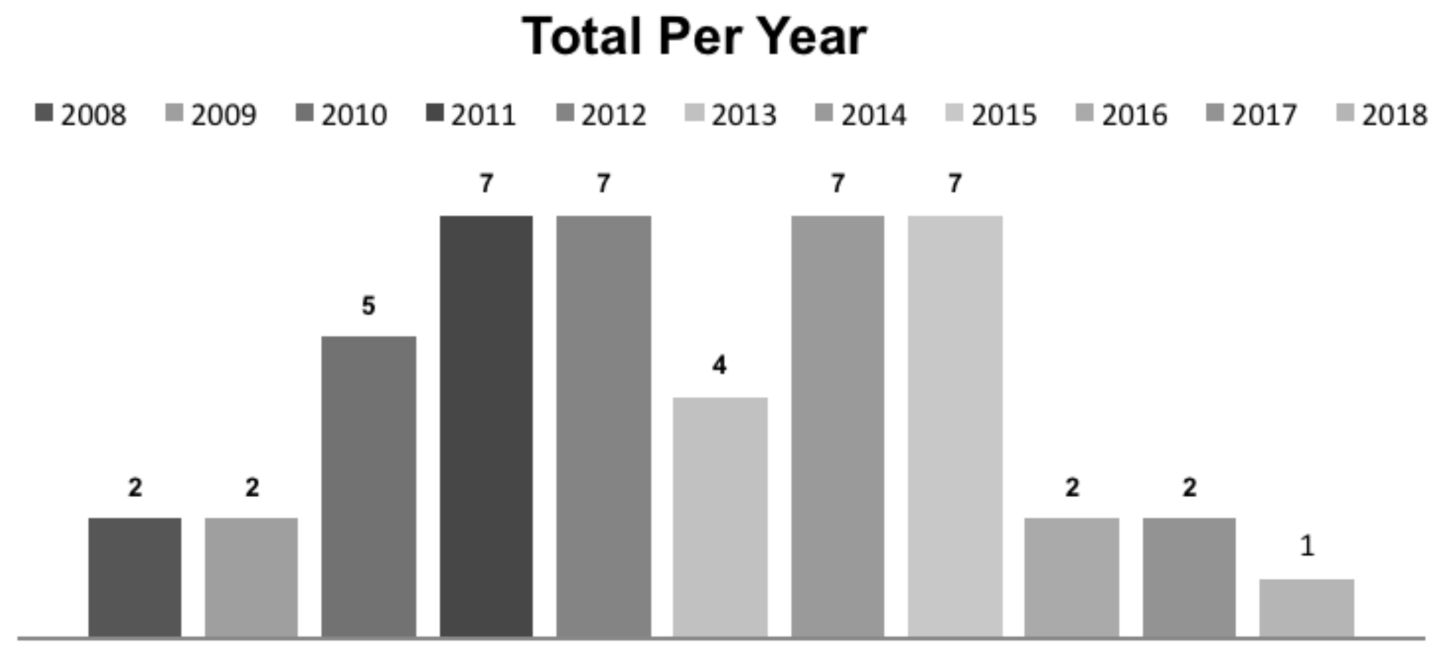

Fig. 2. Cumulative Graph.

PubMed

\section{RESULTS}

Through the review, all studies showed that the most critical stage in the preparation of a dental prosthesis is to take a dental impression. The conventional impression technique consists of obtaining a negative of the intra-oral situation that will be poured into gypsum, obtaining a positive copy, on which the work will be carried out. This technique presented some disadvantages such as: the need of many impression repetitions times, inaccurate technique and mold distortion for the model. Threedimensional dental impresion systems have emerged to solve some problems encountered in the conventional technique (Cook \& Fasbinder, 2012).

In comparative studies evaluating the accuracy of gypsum models obtained from conventional than digital dental impression, several anatomical areas were analyzed, and the gypsum models showed less distortions. Therefore, a similarity was observed between the both models, since both presented values close to the reference model, and the gypsum models had better reproductive details of secondary areas (Ender \& Mehl, 2011, 2013; Dehurtevent et al., 2015).

Researches evaluating the accuracy of conventional and digital impression methods for a complete dental arch, comparing 8 different types of conventional impression materials and digital systems. The results showed that among the systems and impression materials compared, the ones with the best performance were the CEREC system and the mercaptans. Those that had worse result were the polyether and alginate. Therefore, the digital systems did not prove superior to the conventional moldings. Note that digital systems are as accurate as conventional impressions. In their studies they also evaluated that the impression with multiple dental implants showed better results than single implants (Fasbinder, 2012; Galhano et al., 2012; Ender \& Mehl, 2015).

Studies have been conducted to assess efficiency, difficulties, and preference in comparison betwen digital systems and conventional impression techniques for a single implant. The efficiency was evaluated by the time taken to make the impression (Gan et al., 2016). The difficulties observed by the patient were assessed through the application of a questionnaire with an evaluation scale. A multiple choice questionnaire was applied to evaluate the operator's preferred technique. The study showed the digital impression technique has a much shorter working time than conventional impression techniques, in addition to the need for fewer repetitions (Ghaeminia et al., 2011). Regarding patient preference, on a scale from 0 to 100 , the average for conventional was lower than digital impression was 30.63. Regarding the operator preference, $60 \%$ preferred the digital technique. Therefore, the studies concluded that the digital technique was more efficient and more comfortable to the patient, besides being preferred by the operator (Güth et al., 2013). 
In a similar study comparing the efficiency and comfort of the patient in the two dental impression techniques (conventional and digital). it is concluded that the total treatment time using the conventional impression technique is longer than digital impression technique, being one of the factors that led $100 \%$ of the subjects to prefer digital technique (Imbery et al., 2010).

Some studies have evaluated the main types of digital scanners, among them: Cerec system, E4D Dentist, iTero and Lava C.O.S. The Cerec System combines a 3D digital scanner with a dental milling machine. It presents as advantages: reduction of the number of appointments and clinical time, possibility of conclusion of the treatment in a single session and patient comfort. Some disadvantages of the system are: the need for gingival retraction and hemostasis and the need to use titanium dioxide powder to perform digital scanning (Kim et al., 2015).

This system, unlike Cerec, does not need a reflecting agent for a good scanning, besides allowing the mouth and gypsum models scan, giving more versatility to the system. When compared to scanner design, the E4D system has a smaller vertical profile, which allows good scanning with minimal mouth opening.

The iTero system consists of a computer and a scanner. Like the E4D system, this system does not need reflective agent. The scanning is guided by a voice command. The system Lava C.O.S presents as novelty in relation to the other systems the image capture mode, which does not use laser or light, reducing distortions. All the systems have as disadvantage the high cost, which still restricts their introduction in the reality of the dental offices (Kim et al., 2013).

\section{DISCUSSION}

In a study aimed at comparing the accuracy of gypsum models obtained from conventional impression, addition silicone (Aquasil Ultra Monophase, Dentsplay) with models obtained from 3D impression, i-Tero (Cadent iteroTM). All data obtained was paired and imported into an inspection software (Geomagic Qualify). It is concluded that digital impression models are similar to conventional models in most anatomical areas, except in secondary areas such as grooves and pits, where gypsum models can reproduce more detail (Kuhr et al., 2016).
In vitro studies with the objective of comparing the marginal and internal accuracy of ceramic crowns obtained from three digital printing systems (LAVA COS (3M), CEREC (Sirona) and iTero (Straumann)) and two conventional molding techniques. For this study, a model of stainless steel jaw was made, where the 16 element was replaced by a tooth model with a bevelled preparation, with a height of $2 \mathrm{~mm}$ and conical area at the top. Ten fingerprints were made with the digital systems Lava C.O.S, CEREC AC and iTero, following the manufacturer's recommendations. The final data obtained were sent to the laboratory for milling and confection of the total ceramic crowns. For conventional molds, the molds were made with addition silicone (Express 2 Penta Putty, 3M) by molding 10- and 10step molds using the 2-step technique. After the casting, the models were scanned and the ceramic crowns were milled and made from the obtained data. Once made, the crowns went through measurement processes for analysis of the marginal settlement and internal adjustment (Librizzi et al., 2011; Lee \& Gallucci, 2013; Lee et al., 2014, 2015).

One study compared the accuracy of digital and conventional dental techniques performed on a model with 5 pre-foraminal implants (Straumann, Basel, Switzerland) simulating a clinical situation. This model was used as control. For conventional impression the polyether (Impregum) was used following all manufacturer's guidelines. The technique of impression was done in two ways: with implants splinted and not splinted. The models were cast and the models obtained with the analogues in position. Digital scanning was done using a digital scanner (TRIOS, 3shape) and the digital models obtained. 5 groups were created for analysis containing 10 models each divided as follows: (I) conventional internal connection splinted impression, (ii) conventional internal connection not splinted impression, (iii) digital scanning, (iv) conventional external connection splinted impression and (v) conventional external connection not splinted impression. The gypsum models obtained from the conventional impression were scanned and matched with models of the digital moldings. Data were analyzed by software. Statistically significant differences were found between groups ii and control. No statistically significant differences were found between groups $i$, iii, iv and $v$ when compared to the control group. The study concluded that digital system did not prove superior than conventional impression. Impression with splinted implants presented better results than not splinted (Miyazaki et al., 2009; Naitoh et al., 2010; Meija et al., 2017). 
An in vitro study compared 8 types of conventional and digital impression materials to evaluate the accuracy of conventional and digital dental impression methods for a complete dental arch. A reference model was used, whose morphology and geometry were known, and this one was used for the impressions taken. The impressions obtained were then compared with the original geometry of the reference model. Among the test groups of conventional and digital materials, the ones with the highest accuracy were CEREC (Siroma Dental GmBH) and mercaptan. Conventional impressions showed high accuracy in all groups, except in the polyether and alginate group. The digital impression showed some deviations from the reference model. The study concluded that conventional and digital impression methods showed differences in accuracy. Digital intraoral impression systems did not exhibit superior accuracy when compared to conventional techniques with high quality materials. However, they offer excellent clinical results, within their indications, by applying the correct scanning technique (Orentlicher et al., 2010).

For a comparison of digital and conventional impression techniques with regard to patient preference and comfort, twenty-four patients (12 men and 12 women) were selected according to inclusion criteria: never had contact with any type of conventional or digital impression, good general and oral health. The conventional impression process was performed following the steps: one operator selected the tray for both jaws with polyether (Impregum 3M) following the manufacturer's handling guidelines. An inter-occlusal record was also made. Efficacy and clinical outcomes were assessed by measuring the time of total treatment time ranging from tray selection to interocclusal recording. Immediately following clinical procedures, the patient was assessed for their perception of the conventional techniques procedure through the use of a standardized stress scale. The digital impression technique was performed in the same patients 2 to 3 weeks after the conventional procedure. The digital impression was performed using the CEREC (Siroma Dental $\mathrm{GmBH}$ ) system. Two virtual models were scanned and constructed, as was the interocclusal record, following the manufacturer's guidelines. Efficacy and clinical outcomes were assessed by measuring the time of total treatment time ranging from filling patient data to interocclusal recording. Immediately after the clinical procedures, the patient was assessed for their perception of the digital procedure through the use of a standardized stress scale. All patients, after performing the conventional and digital impressions, answered a comparative questionnaire between the two techniques. The results showed that digital are more efficient than conventional impression techniques, and have been preferred by $100 \%$ of the patients studied in the research. Therefore, the study concludes that the total treatment time using the conventional impression technique is longer when compared to the digital system, being one of the factors that led the subjects to prefer digital impression (Polido, 2010; Papaspyridakos et al., 2016; Rutkunas et al., 2017).

The search for precise and stable impression material has always been a challenge in the history of dentistry. In 1937, the reversible hydrocolloid appeared and, a short time later, the irreversible hydrocolloid, but both presented low dimensional stability (Sannino et al., 2014). The polysulfides were created soon after, but due to the unpleasant odor and taste, they were not well accepted by the patients. In 1965, polyether was introduced as the first material developed specifically for dental impression, which had acceptable prey time, was hydrophilic and had excellent detail reproduction, however the models should be done within $48 \mathrm{~h}$ due to deformation the material underwent (Sason et al., 2018).

Subsequently, the condensation silicones were created, however, they presented low dimensional stability. Then, the addition silicones have brought a great advance as a high modulus of elasticity, good reproduction of details, pleasant odor and taste. However, in addition to all the properties of the materials, impression technique, material handling, mold transfer to the laboratory are factors that influence the final precision of the prosthetic crown (Schaefer et al., 2014) (Fig. 3).

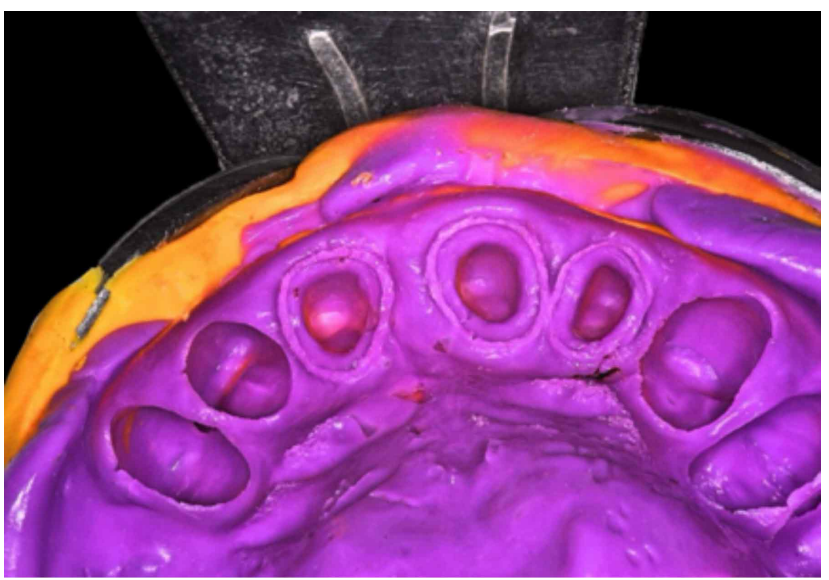

Fig. 3. Conventional dental impression with addition silicone material. 
The mouth scanners appear in this context as a revolution, aiming at a precise, safe and comfortable technique for the patient. The digital systems in this study were: Cerec system, E4D Dentist, iTero, Lava C.O.S. The Cerec system combined a 3D digital scanner with a milling machine capable of sculpting ceramic blocks in one session. This speeds up the treatment and eliminates some queries. This system scans the tooth preparation, makes a digital model, waxes restoration based on adjacent teeth and antagonist teeth, and allows the dentist to make changes (Seelbach et al., 2013) (Figs. 4. A, B, C). For good scanning, gingival tissue retraction, hemostasis, and use of a biocompatible titanium dioxide powder are required to coat the entire area to be scanned to allow the recording camera to copy all tissues. The image obtained is sent to a computer, where the dentist can see it at all angles and approximations. The program
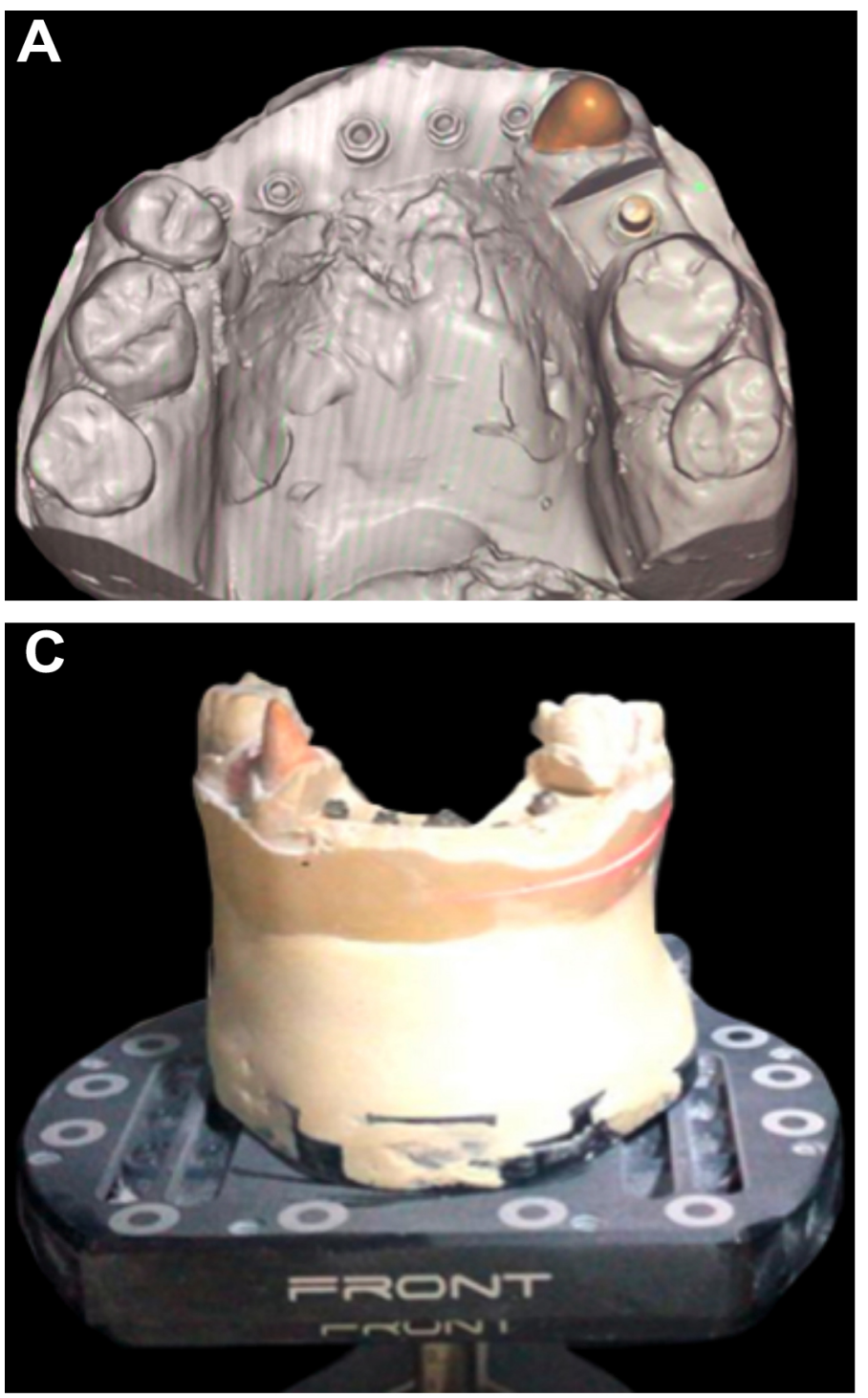

suggests a restorative model, which can be adjusted by the dentist; after the restoration model has been defined, the information is sent to the router that will shape the ceramic block (Sherrard et al., 2010).

The E4D system, developed by D4D Technologies LLC (Dallas, TX) in 2008, consists of a design center (computer and monitor), a laser scanner, a milling unit, a communication server and a router. The scanner of this system has a vertical profile smaller than CEREC system, so that the patient does not need to make a wide mouth opening for scanning the posterior teeth. It is not necessary to use a reflecting agent, such as titanium dioxide, for a good scan. This system allows the scanning of the mouth, impressions and gypsum models. Similar to the CEREC system, the E4D system has a system that sends the information collected to a computer, which will make a restoration

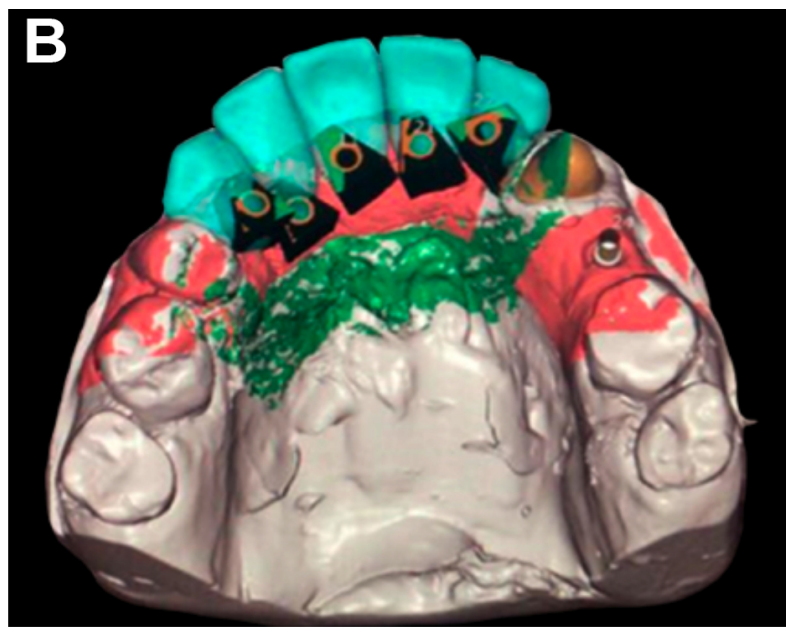

on the scanned model, which can be altered by the dentist (Timock et al., 2011). The iTero (Cadent) system consists of a computer, monitor, pedal and scanner. The scanner works by the emission of light beams that when it comes into contact with a surface at a certain distance reflects the light and forms the image, not needing a reflecting substance; a voice command guides the dentist to make the intraoral series of scans. The images are sent to the computer where it is possible to construct the restoration design and send the information for milling (Ting-Shu \& Jian, 2015).

Fig. 4. A. Gypsum model for digital scanning impression B. Scanned 3D digital model. C. Digital prosthetic 3D model planning. 
The Lava C.O.S (3M ESPE) system incorporates advanced optical design. Unlike other systems that use laser or light, which bring greater distortion and are slower, the Lava C.O.S captures scanned images quickly and creates high resolution virtual models. The captured images are sent to a computer where it is possible to select the shape of the restoration and modifications by the dentist. All information is sent to the router that will shape the ceramic block (Van der Meer et al., 2012).

The cost of these systems ranges from a little more than US $\$ 20,000$ to more than US $\$ 100,000$, and is still a very expensive material. The author concludes that it is the 3D digital scanning technology has advanced a lot in recent years and has brought great advances to the dentistry and quality of its work and that even at high cost, can no longer be ignored by dentists (Walker et al., 2010).

In an evaluation of the efficiency, difficulties, and preference of digital and conventional impression techniques for a single implant were compared. The studys showed that: digital impression proved to be a more efficient technique than conventional when the total time of treatment was evaluated; the digital system required fewer reps, which helped reduce the final treatment time; the difficulty of the technique was less for digital than conventional impression when performed by inexperienced operators (Yamada et al., 2011; Flügge et al., 2013; Yuzbasioglu et al., 2014; Chochlidakis et al., 2016; Rudolph et al., 2016; Renne et al., 2017).

\section{CONCLUSION}

It can be concluded from this study that digital scanning systems were not superior to conventional impression when comparing fidelity, accuracy and detail reproduction; but, have proved to be superior to conventional techniques for clinical chair time, patient and operator preference, and patient comfort. Nevertheless, the high cost of these systems still hinders their introduction into the clinical reality.

CARVALHO, T. F.; LIMA, J. F. M.; DE MATOS, J. D. M.; LOPES, G. R. S.; DE VASCONCELOS, J. E. L.; ZOGHEIB, L. V. \& DE CASTRO, D. S. M. Evaluación de la exactitud de los métodos convencionales y digitales de la obtención de impresiones dentales. Int. J. Odontostomat., 12(4):368-375, 2018.
RESUMEN: El objetivo de este estudio consistió en realizar una revisión bibliográfica sobre la precisión de los métodos de moldeo dental convencionales y digitales, así como presentar los diversos sistemas de escaneo intraoral tridimensionales. Se realizó una búsqueda bibliográfica en la base de datos de salud principal de PUBMED en la cual se recopilaron trabajos publicados entre 2008 y 2018 . Se incluyeron estudios de laboratorio, informes de casos y revisiones sistemáticas, abordando temas que tratan con materiales digitales convencionales, moldeo y precisión. Se excluyeron los artículos que no evaluaron los materiales de moldeo, su comportamiento y técnicas para obtener una buena impresión de las estructuras orales. A través de una revisión exhaustiva en la literatura, obtuvimos los siguientes hallazgos: el paso más crítico en la preparación de una pieza protésica es la impresión de la preparación. La técnica convencional de moldeo consiste en obtener una copia negativa de la situación intraoral que se verterá en el yeso, obteniendo una copia positiva, sobre la cual se realizará el trabajo. Resulta que los sistemas de escaneo digital no fueron superiores a las molduras convencionales al comparar la fidelidad, precisión y reproducción de detalles; en cambio, fueron superiores a las molduras convencionales al considerar el tiempo de trabajo clínico, la preferencia del paciente y del operador y la comodidad del paciente.

PALABRAS CLAVE: técnica de impresión dental; tecnología odontológica; impresión tridimensional.

\section{REFERENCES}

Aragón, M. L.; Pontes, L. F.; Bichara, L. M.; Flores-Mir, C. \& Normando, D. Validity and reliability of intraoral scanners compared to conventional gypsum models measurements: a systematic review. Eur. J. Orthod., 38(4):429-34, 2016

Baba, N. Z.; Goodacre, C. J.; Jekki, R. \& Won, J. Gingival displacement for impression making in fixed prosthodontics: contemporary principles, materials, and techniques. Dent. Clin. North Am., 58(1):4568, 2014.

Bauman, R.; Scarfe, W.; Clark, S.; Morelli, J.; Scheetz, J. \& Farman, A. Ex vivo detection of mesiobuccal canals in maxillary molars using CBCT at four different isotropic voxel dimensions. Int. Endod. J., 44(8):752-8, 2011.

Birnbaum, N. S. \& Aaronson, H. B. Dental impressions using 3D digital scanners: virtual becomes reality. Compend. Contin. Educ. Dent., 29(8):494-505, 2008

Chochlidakis, K. M.; Papaspyridakos, P.; Geminiani, A.; Chen, C. J.; Feng, I. J. \& Ercoli, C. Digital versus conventional impressions for fixed prosthodontics: A systematic review and meta-analysis. J. Prosthet. Dent., 116(2):184-90, 2016.

Christensen, G. J. Impressions are changing: deciding on conventional, digital or digital plus in-office milling. J. Am. Dent. Assoc., 140(10):1301-4, 2009.

Christensen, G. J. In-office CAD/CAM milling of restorations: the future? J. Am. Dent. Assoc., 139(1):83-5, 2008.

Cook, K. T. \& Fasbinder, D. J. Accuracy of CAD/CAM crown fit with infrared and LED cameras. Int. J. Comput. Dent., 15(4):315-26, 2012.

Dehurtevent, M.; Robberecht, L. \& Béhin, P. Influence of dentist experience with scan spray systems used in direct CAD/CAM impressions. J. Prosthet. Dent., 113(1):17-21, 2015. 
Ender, A. \& Mehl, A. Accuracy of complete-arch dental impressions: a new method of measuring trueness and precision. J. Prosthet. Dent., 109(2):121-8, 2013.

Ender, A. \& Mehl, A. Full arch scans: conventional versus digital impressions--an in-vitro study. Int. J. Comput. Dent., 14(1):11-21, 2011.

Ender, A. \& Mehl, A. In-vitro evaluation of the accuracy of conventional and digital methods of obtaining full-arch dental impressions. Quintessence Int., 46(1):9-17, 2015.

Fasbinder, D. Using digital technology to enhance restorative dentistry. Compend. Contin. Educ. Dent., 33(9):666-8, 2012.

Flügge, T. V.; Schlager, S.; Nelson, K.; Nahles, S. \& Metzger, M. C. Precision of intraoral digital dental impressions with iTero and extraoral digitization with the iTero and a model scanner. Am. J. Orthod. Dentofacial Orthop., 144(3):471-8, 2013.

Galhano, G. Á.; Pellizzer, E. P. \& Mazaro, J. V. Optical impression systems for CAD-CAM restorations. J. Craniofac. Surg., 23(6):e575-9, 2012.

Gan, N.; Xiong, Y. \& Jiao, T. Accuracy of intraoral digital impressions for whole upper jaws, including full dentitions and palatal soft tissues. PloS One, 11(7):e0158800, 2016.

Ghaeminia, H.; Meijer, G. J.; Soehardi, A.; Borstlap, W. A.; Mulder, J.; Vlijmen, O. J.; Bergé, S. J. \& Maal, T. J. The use of cone beam CT for the removal of wisdom teeth changes the surgical approach compared with panoramic radiography: a pilot study. Int. J. Oral Maxillofac. Surg., 40(8):834-9, 2011.

Güth, J. F.; Keul, C.; Stimmelmayr, M.; Beuer, F. \& Edelhoff, D. Accuracy of digital models obtained by direct and indirect data capturing. Clin. Oral Investig., 17(4):1201-8, 2013.

Imbery, T. A.; Nehring, J.; Janus, C. \& Moon, P. C. Accuracy and dimensional stability of extended-pour and conventional alginate impression materials. J. Am. Dent. Assoc., 141(1):32-9, 2010.

Kim, J. H.; Kim, K. B.; Kim, S. H.; Kim, W. C.; Kim, H. Y. \& Kim, J. H. Quantitative evaluation of common errors in digital impression obtained by using an LED blue light in-office CAD/CAM system. Quintessence Int., 46(5):401-7, 2015.

Kim, S. Y.; Kim, M. J.; Han, J. S.; Yeo, I. S.; Lim, Y. J. \& Kwon, H. B. Accuracy of dies captured by an intraoral digital impression system using parallel confocal imaging. Int. J. Prosthodont., 26(2):161-3, 2013.

Kuhr, F.; Schmidt, A.; Rehmann, P. \& Wöstmann, B. A new method for assessing the accuracy of full arch impressions in patients. J. Dent., 55:68-74, 2016.

Lee, S. J., \& Gallucci, G. O. Digital vs. conventional implant impressions: efficiency outcomes. Clin. Oral Implants Res., 24(1):111-5, 2013.

Lee, S. J.; Betensky, R. A.; Gianneschi, G. E. \& Gallucci, G. O. Accuracy of digital versus conventional implant impressions. Clin. Oral Implants Res., 26(6):715-9, 2015

Lee, W. S.; Kim, W. C.; Kim, H. Y.; Kim, W. T. \& Kim, J. H. Evaluation of different approaches for using a laser scanner in digitization of dental impressions. J. Adv. Prosthodont., 6(1):22-9, 2014.

Librizzi, Z. T.; Tadinada, A. S.; Valiyaparambil, J. V.; Lurie, A. G. \& Mallya, S. M. Cone-beam computed tomography to detect erosions of the temporomandibular joint: Effect of field of view and voxel size on diagnostic efficacy and effective dose. Am. J. Orthod. Dentofacial Orthop., 140(1):e25-30, 2011.

Miyazaki, T.; Hotta, Y.; Kunii, J.; Kuriyama, S. \& Tamaki, Y. A review of dental CAD/CAM: current status and future perspectives from 20 years of experience. Dent. Mater. J., 28(1):44-56, 2009.

Naitoh, M.; Nakahara, K.; Suenaga, Y.; Gotoh, K.; Kondo, S. \& Ariji, E. Comparison between cone-beam and multislice computed tomography depicting mandibular neurovascular canal structures. Oral Surg. Oral Med. Oral Pathol. Oral Radiol. Endod., 109(1):e25-31, 2010.

Orentlicher, G.; Goldsmith, D. \& Horowitz, A. Applications of 3-dimensional virtual computerized tomography technology in oral and maxillofacial surgery: current therapy. J. Oral Maxillofac. Surg., 68(8):1933-59, 2010.

Papaspyridakos, P.; Gallucci, G. O.; Chen, C. J.; Hanssen, S.; Naert, I. \& Vandenberghe, B. Digital versus conventional implant impressions for edentulous patients: accuracy outcomes. Clin. Oral Implants Res., 27(4):465-72, 2016.
Polido, W. D. Digital impressions and handling of digital models: the future of dentistry. Dent. Press J. Orthod., 15(5):18-22, 2010.

Renne, W.; Ludlow, M.; Fryml, J.; Schurch, Z.; Mennito, A.; Kessler, R. \& Lauer, A. Evaluation of the accuracy of 7 digital scanners: An in vitro analysis based on 3-dimensional comparisons. J. Prosthet. Dent., 118(1):36-42, 2017.

Rudolph, H.; Salmen, H.; Moldan, M.; Kuhn, K.; Sichwardt, V.; Wöstmann, B. \& Luthardt, R. G. Accuracy of intraoral and extraoral digital data acquisition for dental restorations. J. Appl. Oral Sci., 24(1):85-94, 2016.

Rutkunas, V.; Geciauskaite, A.; Jegelevicius, D. \& Vaitiekunas, M. Accuracy of digital implant impressions with intraoral scanners. A systematic review. Eur. J. Oral Implantol., 10 Suppl. 1:101-20, 2017.

Sannino, G.; Germano, F.; Arcuri, L.; Bigelli, E.; Arcuri, C. \& Barlattani, A. CEREC CAD/CAM Chairside System. Oral Implantol. (Rome), 7(3):57-70, 2014.

Sason, G. K.; Mistry, G.; Tabassum, R. \& Shetty, O. A comparative evaluation of intraoral and extraoral digital impressions: An in vivo study. J. Indian. Prosthodont. Soc., 18(2):108-16, 2018.

Schaefer, O.; Decker, M.; Wittstock, F.; Kuepper, H. \& Guentsch, A. Impact of digital impression techniques on the adaption of ceramic partial crowns in vitro. J. Dent., 42(6):677-83, 2014.

Seelbach, P.; Brueckel, C. \& Wöstmann, B. Accuracy of digital and conventional impression techniques and workflow. Clin. Oral Investig., 17(7):1759-64, 2013.

Sherrard, J. F.; Rossouw, P. E.; Benson, B. W.; Carrillo, R. \& Buschang, P. H. Accuracy and reliability of tooth and root lengths measured on cone-beam computed tomographs. Am. J. Orthod. Dentofacial Orthop., 137(4 Suppl.):S100-8, 2010.

Timock, A. M.; Cook, V.; McDonald, T.; Leo, M. C.; Crowe, J.; Benninger, B. L. \& Covell, D. A. Jr. Accuracy and reliability of buccal bone height and thickness measurements from cone-beam computed tomography imaging. Am. J. Orthod. Dentofacial Orthop., 140(5):734-44, 2011.

Ting-Shu, S. \& Jian, S. Intraoral digital impression technique: a review. J. Prosthodont., 24(4):313-21, 2015.

van der Meer, W. J.; Andriessen, F. S.; Wismeijer, D. \& Ren, Y. Application of intra-oral dental scanners in the digital workflow of implantology. PloS One, 7(8):e43312, 2012.

Walker, M. P.; Burckhard, J.; Mitts, D. A. \& Williams, K. B. Dimensional change over time of extended-storage alginate impression materials. Angle Orthod., 80(6):1110-5, 2010.

Yamada, T.; Ishihama, K.; Yasuda, K.; Hasumi-Nakayama, Y.; Ito, K.; Yamaoka, M. \& Furusawa, K. Inferior alveolar nerve canal and branches detected with dental cone beam computed tomography in lower third molar region. J. Oral Maxillofac. Surg., 69(5):1278-82, 2011.

Yuzbasioglu, E.; Kurt, H.; Turunc, R. \& Bilir, H. Comparison of digital and conventional impression techniques: evaluation of patients' perception, treatment comfort, effectiveness and clinical outcomes. B. M. C. Oral Health, 14:10, 2014.

\section{Corresponding author:}

Daniel Sartorelli Marques de Castro

D.D.S.; M.D.; Ph.D.

Professor of Prosthodontics

Department of Dentistry

Christus University Center - UNICHRISTUS

Fortaleza - CE

BRAZIL

Email: matosjefferson19@gmail.com

Recibido : 27-05-2018

Aceptado: 06-08-2018 